\title{
The therapeutic efficacy of S-1 against orthotopically implanted human pleural mesothelioma cells in severe combined immunodeficient mice
}

\author{
Trung The Van • Masaki Hanibuchi - Soji Kakiuchi - Seidai Sato • \\ Takuya Kuramoto - Hisatsugu Goto - Atsushi Mitsuhashi • Yasuhiko Nishioka • \\ Shin-ichi Akiyama · Saburo Sone
}

Received: 9 June 2010/ Accepted: 26 October 2010/Published online: 16 November 2010

(C) The Author(s) 2010. This article is published with open access at Springerlink.com

\begin{abstract}
Purpose Malignant pleural mesothelioma (MPM) is a highly lethal neoplasm. S-1 has been developed as a novel oral antineoplastic agent based on the modulation of 5fluorouracil (5-FU) bioactivity. This study was conducted to investigate the preclinical therapeutic effect of S-1 on MPM.

Methods We used three human MPM cell lines, YMESO-14, NCI-H290 and MSTO-211H. In vitro proliferation of human MPM cells was determined by MTT assay. Human MPM cells were orthotopically implanted into thoracic cavity of SCID mice. Tumor-bearing mice were treated with S-1 or vehicle.

Results The combination of 5-FU and 5-chloro-2,4-dihydroxypyridine (CDHP) was more effective than 5-FU alone in inhibiting MPM cell proliferation in vitro. This combination was most effective in Y-MESO-14 cells, which co-expressed high protein level of dihydropyrimidine dehydrogenase (DPD) and thymidine phosphorylase (TP). In vivo data showed that treatment with S-1 significantly reduced thoracic tumors and pleural effusion produced by Y-MESO-14 cells. Moreover, treatment with S-1
\end{abstract}

T. T. Van - S. Kakiuchi - S. Sato - T. Kuramoto - S. Akiyama

S. Sone

Department of Medical Oncology, Institute of Health

Biosciences, University of Tokushima Graduate School,

3-18-15 Kuramoto-cho, Tokushima 770-8503, Japan

M. Hanibuchi · H. Goto · A. Mitsuhashi - Y. Nishioka •

S. Sone $(\square)$

Department of Respiratory Medicine and Rheumatology,

Institute of Health Biosciences, University of Tokushima

Graduate School, 3-18-15 Kuramoto-cho,

Tokushima 770-8503, Japan

e-mail: ssone@clin.med.tokushima-u.ac.jp prolonged the survival of Y-MESO-14 cell-bearing SCID mice.

Conclusions We demonstrated that S-1 was effective for inhibiting the proliferation of MPM cells, particularly with both DPD and TP expressions, suggesting that S-1 might be therapeutically effective for control of MPM.

Keywords S-1 - Malignant pleural mesothelioma · Orthotopic implantation model · Anti-tumor activity
Abbreviations
MPM Malignant pleural mesothelioma
5-FU 5-fluorouracil
FT Tegafur
CDHP 5-chloro-2,4-dihydroxypyridine
OXO Potassium oxonate
DPD Dihydropyrimidine dehydrogenase
FUTP 5-fluorouridine-5'-triphosphate
TP Thymidine phosphorylase
FBS Fetal bovine serum
HUVEC Human umbilical vein endothelial cells
HPMC Hydroxypropyl methylcellulose
MTT 3-(4,5-dimethylthiazol-2-yl)-2,5-diphenyl tetrazolium
PVDF Polyvinylidene difluoride
PBS Phosphate-buffered saline
FdUMP 5-fluoro-2'deoxyuridine-5'-monophosphate

\section{Introduction}

Malignant pleural mesothelioma (MPM) is a highly aggressive fatal malignancy which closely related to 
previous exposure to asbestos [1-3]. MPM was once considered rare, but its incidence is increasing worldwide, with expected peak before 2020 in Europe [4, 5] or around 2030-2040 in Asia [6, 7].

The management of MPM is still very challenging by lack of sufficient treatment option. In addition, because of the delayed manifestation and the insidiously progressive nature of this disease, the patients at the time of diagnosis are often older and often have advanced stages. As a result, chemotherapeutics have become the mainstay approach for treatment of this disease $[8,9]$. Although the multi-targeted antifolate agent, pemetrexed, in combination with cisplatin, was recently approved as first-line treatment against MPM, the overall prognosis of patients with MPM still remains very poor $[10,11]$. Therefore, the development and testing of new antitumor agents for the treatment of MPM are definitely pressing.

S-1 is a novel fluoropyrimidine anticancer agent with dual actions, designed to enhance the anticancer activity of 5-fluorouracil (5-FU) and reduce its gastrointestinal toxicity through the deliberate combination of the following components: an oral fluoropyrimidine agent tegafur (FT) and two enzyme inhibitors 5-chloro-2,4-dihydroxypyridine (CDHP) and potassium oxonate (OXO) in a molar ratio of 1:0.4:1 [12]. CDHP, a pyrimidine derivative and a reversible competitive inhibitor of dihydropyrimidine dehydrogenase (DPD), is about 180 times more potent than uracil in inhibiting DPD in both the tumor and the liver, thus allowing greater concentrations of 5-FU to go through the anabolic pathway, producing the active metabolites [13]. OXO localizes in the gastrointestinal mucosal tract and selectively inhibits the enzyme pyrimidine phosphoribosyl transferase, which converts 5-FU to 5-flourouridine 5'-monophosphate (FUMP), and consequently attenuates gastrointestinal toxicity [14]. Phase II trials have demonstrated that S-1, as a single agent, has superior antitumor effect for the treatment of gastric, colorectal, head and neck, breast, non-small cell lung, and pancreatic cancers, especially gastrointestinal tumors which often highly express DPD [15-18]. However, to our knowledge, there has been no study addressing the effect of S-1 on MPM.

The aim of this study was to investigate the preclinical therapeutic ability of S-1 against MPM in relation to the expression of DPD and/or thymidine phosphorylase (TP). By using an orthotopic implantation model, we examined whether S-1 could reduce the production of thoracic tumors and pleural effusion produced by human MPM cells. Treatment with S-1 significantly suppressed the progression of MPM cells, particularly with both DPD and TP expressions, and prolonged survival of MPM-bearing SCID mice.

\section{Materials and methods}

\section{Cell cultures}

The human MPM cell line Y-MESO-14 was established as described previously [19]. The human MPM cell lines NCI-H290 and MSTO-211H cells were purchased from American Type Culture Collection (Manassas, VA). These tumor cell lines were maintained in RPMI1640 (Nissui Pharmaceutical Co., Tokyo, Japan) supplemented with $10 \%$ heat-inactivated fetal bovine serum (FBS; GIBCO, Grand Island, NY), penicillin (100 U/ml), and streptomycin $(50 \mu \mathrm{g} / \mathrm{ml})$. Human umbilical vein endothelial cells (HUVEC) were maintained in EBM-2 medium with growth supplement (Lonza, Walkersville, MD) and used for in vitro experiments at passages 2-4. All cell lines were incubated at $37^{\circ} \mathrm{C}$ in a humidified atmosphere of $5 \% \mathrm{CO}_{2}$.

\section{Reagents}

5-FU was purchased from Wako Pure Chemical Industries Ltd. (Osaka, Japan). S-1, CDHP, and hydroxypropyl methylcellulose (HPMC) were provided by Taiho Pharmaceutical Co., Ltd. (Tokyo, Japan). For in vitro treatment, 5-FU or mixture of 5-FU/CDHP (in a molar ratio of 1:0.4) was dissolved in DMSO before use. The doses of drugs were expressed as the doses of 5-FU. For in vivo treatment, $\mathrm{S}-1$ was dissolved in $0.5 \%$ HPMC solution. The doses of $\mathrm{S}-1$ were expressed as the doses of FT, since FT is the active component.

In vitro cell proliferation assay

Cell proliferation was determined using the 3-(4,5dimethylthiazol-2-yl)-2, 5-diphenyl tetrazolium (MTT) dye reduction method [20]. Briefly, the tumor cells $\left(2 \times 10^{3} /\right.$ well) that had been plated in triplicate in 96-well plates were incubated in RPMI1640 containing 10\% FBS for $24 \mathrm{~h}$ at $37^{\circ} \mathrm{C}$. Next, the cells were incubated for $72 \mathrm{~h}$ in the presence or absence of various concentrations of 5-FU or 5-FU plus CDHP. Then, $50 \mu \mathrm{l}$ of stock MTT solution ( $2 \mathrm{mg} / \mathrm{ml}$; Sigma-Aldrich, St. Louis, MO) was added to each well and cells then were incubated for $2 \mathrm{~h}$. The media containing the MTT solution were removed, and the dark blue crystals were dissolved by adding $100 \mu \mathrm{l}$ of DMSO. Absorbance was measured with a microplate reader (Dainippon Seiyaku, Tokyo, Japan) at test and reference wavelengths of 550 and $630 \mathrm{~nm}$, respectively. The $\mathrm{IC}_{50}$ values resulting from $50 \%$ inhibition of cell growth were calculated. 
Western blotting for determination of DPD and TP protein level

The whole cell extracts were prepared with Ripa lysis buffer (Thermo Fisher Scientific Inc., Rockford, IL), and protein concentrations were measured using Bradford's method. Twenty $\mu \mathrm{g}$ of total cell extract protein were electrophoresed on $4-10 \% \mathrm{NuPAGE}^{\circledR}$ Bis-Tris Mini gels (at 200 Voltage for $40 \mathrm{~min}$ ). Then, proteins were electroblotted onto iBlot $^{\mathrm{TM}}$ gel Tranfer Stacker polyvinylidene difluoride (PVDF) membrane (Invitrogen, Carlsbad, CA) according to manufacturer's instruction. The PVDF membranes were then blocked with a $0.2 \%$ non-fat milk/TrisBuffer Saline Tween 20 solution in blot holders (SNAP i.d ${ }^{\mathrm{TM}}$ Protein Detection System, Millipore, Billerica, MA). Transferred membranes were incubated with mouse monoclonal antibody against human DPD (1:150 dilution, Santa Cruz Biotechnology, Inc., Santa Cruz, CA) or with mouse monoclonal antibody against human TP as described previously [21] or with anti- $\beta$-actin antibody (1:600 dilution; Sigma-Aldrich, St. Louis, MO) at room temperature for $10 \mathrm{~min}$, followed by incubation for $10 \mathrm{~min}$ at room temperature with horseradish peroxidase-conjugated goat antimouse IgG (1:3,000 dilution; Santa Cruz Biotechnology, Inc., Santa Cruz, CA). Protein-antibody conjugates were then developed using enhanced chemiluminescent substrate (Thermo Fisher Scientific Inc., Rockford, IL). Finally, the immunoreactive bands were read under Luminescent Image Analyzer (LAS-4000 mini; Fuji Film, Tokyo, Japan).

\section{Animals}

Male SCID mice, 6-7 weeks old, were obtained from CLEA Japan (Osaka, Japan) and maintained under specific pathogen-free conditions throughout this study. All experiments were performed in accordance with the guidelines of University of Tokushima, Committee on Animal Care and Use.

Orthotopic implantation model

The human MPM cells were harvested and washed with $\mathrm{Ca}^{2+}$ - and $\mathrm{Mg}^{2+}$-free phosphate-buffered saline (PBS; Nissui Pharmaceutical Co., Tokyo, Japan). Cell viability was determined by a trypan blue exclusion test, and only single cell suspensions of $>90 \%$ viability were used. Y-MESO-14 $\left(1 \times 10^{6}\right.$ cells/100 $\mu \mathrm{l}$ PBS/mouse $)$, NCIH290 $\left(3 \times 10^{5}\right.$ cells $/ 100 \mu \mathrm{l} \mathrm{PBS} /$ mouse $)$ or MSTO-211H cells $\left(1 \times 10^{6}\right.$ cells $\left./ 100 \mu \mathrm{l} \mathrm{PBS} / \mathrm{mouse}\right)$ were injected into the thoracic cavity of SCID mice on day 0 [19, 22, 23]. Before S-1 administration, the mice were randomly divided into control and treatment groups. Oral administration of
$\mathrm{S}-1$ (5 or $10 \mathrm{mg} / \mathrm{kg}$ ) or vehicle was given once daily with various treatment schedules. The general condition of tumor-bearing mice was checked every day and their body weights were measured weekly. On day 21 , the mice were killed and the thoracic tumors were weighed. The pleural effusion was harvested using a 1-ml syringe, and its volume was measured.

Immunohistochemical staining for DPD and TP

Mouse tumor tissue samples were fixed in $10 \%$ formalin solution and embedded in paraffin. Deparaffinized 4- $\mu \mathrm{m}$ sections of tissue were heated in citrate buffer $(\mathrm{pH}$ 6.0) for $10 \mathrm{~min}$ followed by incubation with $0.3 \% \mathrm{H}_{2} \mathrm{O}_{2}$ for blocking of endogenous peroxidase. The sections were then incubated with primary mouse monoclonal antibody against human DPD (1:100 dilution, Santa Cruz) or rabbit polyclonal antibody against human TP [21] at $4^{\circ} \mathrm{C}$ overnight. Then, horseradish peroxidase-conjugated speciesspecific secondary antibodies (Amersham Biosciences, Buckinghamshire, UK) were applied for $60 \mathrm{~min}$ at room temperature. Immune complexes were visualized with DAB substrate kit (Vector Laboratories Inc., Burlingame, CA). Negative control was carried out by omitting primary antibody.

\section{Statistical analysis}

The significance of differences in cell proliferation assay was analyzed by the Student's $t$ test (two-tailed). The in vivo data were analyzed using Wilcoxon test and Holm's procedure (Tukey test) test, when applicable. The probability of survival was calculated with the Kaplan-Meier method, and differences between curves were evaluated with the log-rank test. The $P$-values less than 0.05 were considered significant in all experiments.

\section{Results}

CDHP enhanced the antitumor activity of 5-FU in vitro

We examined whether CDHP could enhance the sensitivity of the MPM cell lines to 5-FU. The cells were treated with 5 -FU or 5-FU plus CDHP in various concentrations for $72 \mathrm{~h}$. Cell proliferation was determined by MTT assay as described in Materials and Methods. Means of $\mathrm{IC}_{50}$ values from 3 to 5 independent experiments were compared. The $\mathrm{IC}_{50}$ values of 5 -FU in the presence of CDHP were significantly lower than those of 5-FU alone in treatment of Y-MESO-14 cells $(0.22 \mu \mathrm{g} / \mathrm{ml} ; 95 \%$ confidence interval [CI]: $0.18-0.26$ versus $0.92 \mu \mathrm{g} / \mathrm{ml} ; 95 \%$ CI: $0.75-1.1$ $\mu \mathrm{g} / \mathrm{ml} ; \quad P<0.0001)$ and NCI-H290 cells $(0.41 \mu \mathrm{g} / \mathrm{ml}$; 
95\% CI: $0.34-0.48$ versus $0.59 \mu \mathrm{g} / \mathrm{ml} ; 95 \%$ CI: $0.50-0.70$ $\mu \mathrm{g} / \mathrm{ml} ; P=0.003)$. We observed same tendency in MSTO$211 \mathrm{H}$ cells, though the difference was not significant $(0.57 \mu \mathrm{g} / \mathrm{ml}$; $95 \%$ CI: $0.44-0.74$ versus $0.77 \mu \mathrm{g} / \mathrm{ml} ; 95 \%$ CI: $0.44-1.1 \mu \mathrm{g} / \mathrm{ml} ; P=0.20$ ). These data indicated that CDHP potentiated the effect of 5-FU in inhibiting the proliferation of MPM cells.

Expression of DPD and TP in mesothelioma cell lines

DPD is the rate-limiting enzyme in 5-FU breakdown. One of the most important compounds of S-1 is CDHP, which has ability to inhibit DPD activity. Several lines of evidence suggest that the intracellular expression of DPD is closely involved with superior antitumor activity of S-1 $[13,17]$. On the other hand, TP has also been reported to mediate the sensitivity of cancer cells to 5-FU [24-26]. Thus, we examined the expression level of DPD and TP protein in MPM cell lines. All the three cell lines strongly expressed DPD protein (Fig. 1a, top), which might benefit CDHP-mediated modulation of 5-FU-based treatment observed in results of proliferation assay. The expression level of TP was remarkable in Y-MESO-14 cells, but undetectable in the other two MPM cell lines (Fig. 1a, middle). Among the three MPM cell lines, Y-MESO-14 cells, which expressed both DPD and TP, appeared the most sensitive to 5-FU in the presence of CDHP (the $\mathrm{IC}_{50}$ value of 5-FU plus CDHP was 4 times lower than that of 5-FU alone). These results suggested that the co-expression of DPD and TP might enhance the therapeutic effect of 5-FU combined with CDHP on human MPM cells.

Determination of the expression of DPD and TP in orthotopically implanted MPM cells in SCID mice

The human MPM cells, Y-MESO-14, NCI-H290 or MSTO-211H, were orthotopically inoculated into the thoracic cavity of SCID mice. These MPM cells were able to produce thoracic tumors and bloody pleural effusion. To confirm the expression of DPD and TP in orthotopically implanted MPM cells in SCID mice, immunohistochemical staining for human DPD and human TP was performed. Consistent with the result of Western blotting, thoracic tumors produced by MPM cells expressed comparable DPD levels among three MPM cells, whereas TP expression in tumor from Y-MESO-14 cells was clearly higher than that in tumors from NCI-H290 or MSTO-211H cells (Fig. 1b).
Fig. 1 Expression of DPD and TP protein in human MPM cells. Cell lysates were harvested and subjected in duplicate to Western blotting analysis for DPD and TP.

Images are representatives of three independent experiments with similar results (a).

Thoracic tumors produced by human MPM cells in mice were harvested and subjected to immunohistochemical staining for DPD and TP protein. Images are representatives of two separate experiments with similar results $(\times 200)(\mathbf{b})$

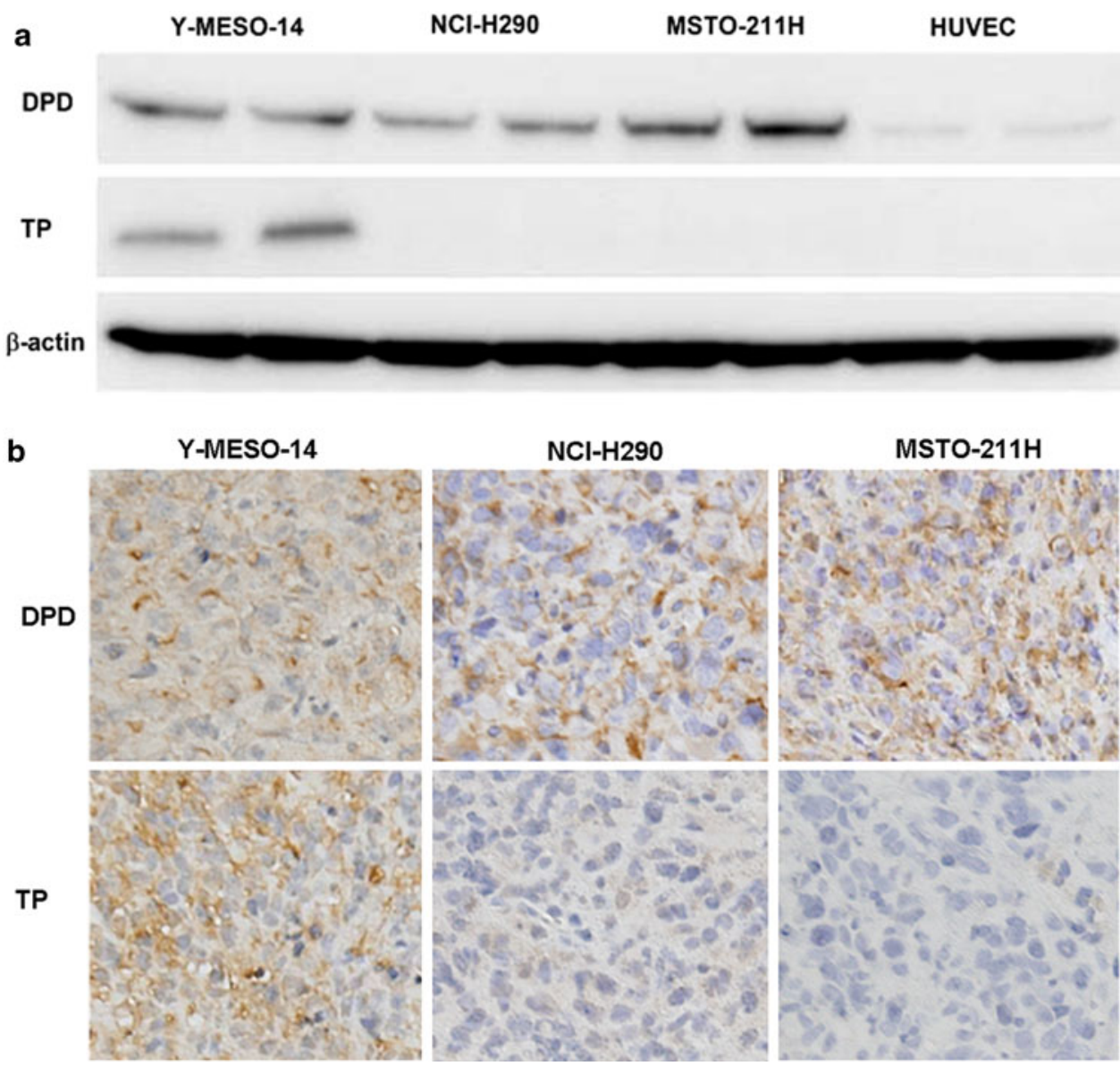


Treatment with S-1 inhibited the production of thoracic tumors and pleural effusion by Y-MESO-14 cells in orthotopic implantation model

To assess the therapeutic effects of S-1, beginning 7 days after MPM cell inoculation, the mice were treated with $\mathrm{S}-1$ $(10 \mathrm{mg} / \mathrm{kg})$, or vehicle (HPMC) as a control, daily for 2 weeks, since we have already confirmed that these MPM cells produced thoracic tumors larger than $1 \mathrm{~mm}$ in diameter at this time [19]. Treatment with S-1 significantly reduced the production of thoracic tumors and pleural effusion in Y-MESO-14 cell-bearing mice compared with vehicle treatment group (Figs. 2a, b, 3). In NCI-H290 cell-
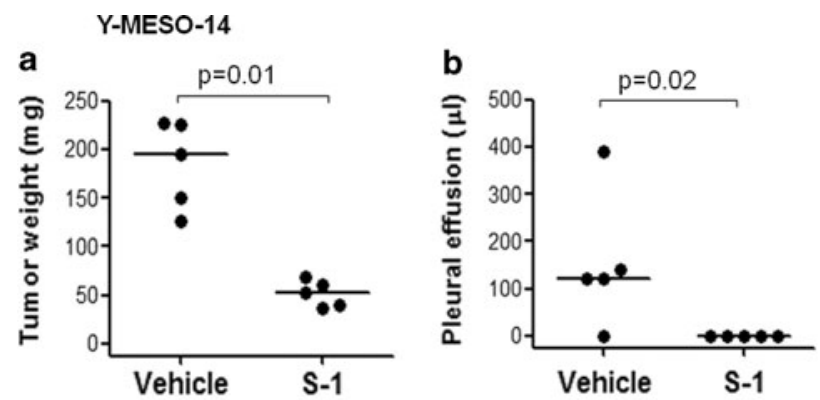

$\mathrm{NCl}-\mathrm{H} 290$
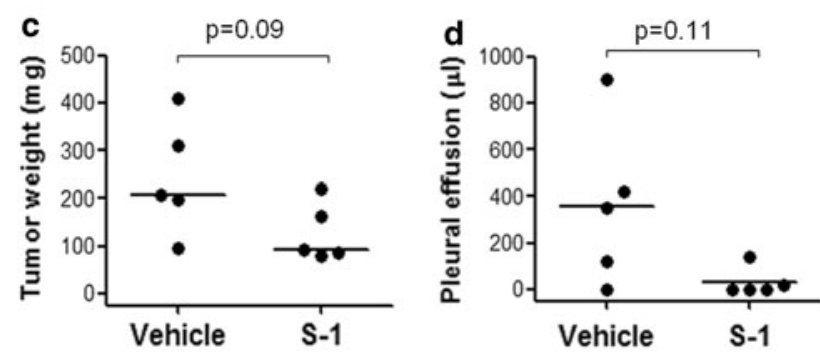

MSTO-211H
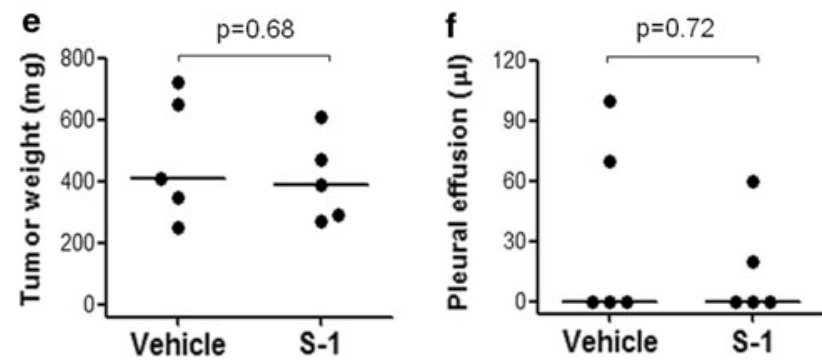

Fig. 2 Therapeutic effect of S-1 on thoracic tumor and pleural effusion produced by MPM cells in SCID mice. Y-MESO-14, NCI$\mathrm{H} 290$, and MSTO-211H cells were inoculated into thoracic cavity of SCID mice on day 0 . The mice were daily treated with vehicle or S-1 $(10 \mathrm{mg} / \mathrm{kg}$ ) for 14 days from day 7 to 20 , and sacrificed on day 21 . Treatment with S-1 significantly reduced tumor and pleural effusion produced by Y-MESO-14 cells $(\mathbf{a}, \mathbf{b})$, but not by NCI-H290 cells $(\mathbf{c}, \mathbf{d})$, and MSTO- $211 \mathrm{H}$ cells $(\mathbf{e}, \mathbf{f})$ in mice. Figure $2 \mathrm{c}$ and $\mathrm{d}$ showed the representative data of three separate experiments with similar results. Figure $2 \mathrm{e}$ and $\mathrm{f}$ showed the representative data of two separate experiments with similar results. The $P$ values were obtained from Wilcoxon test

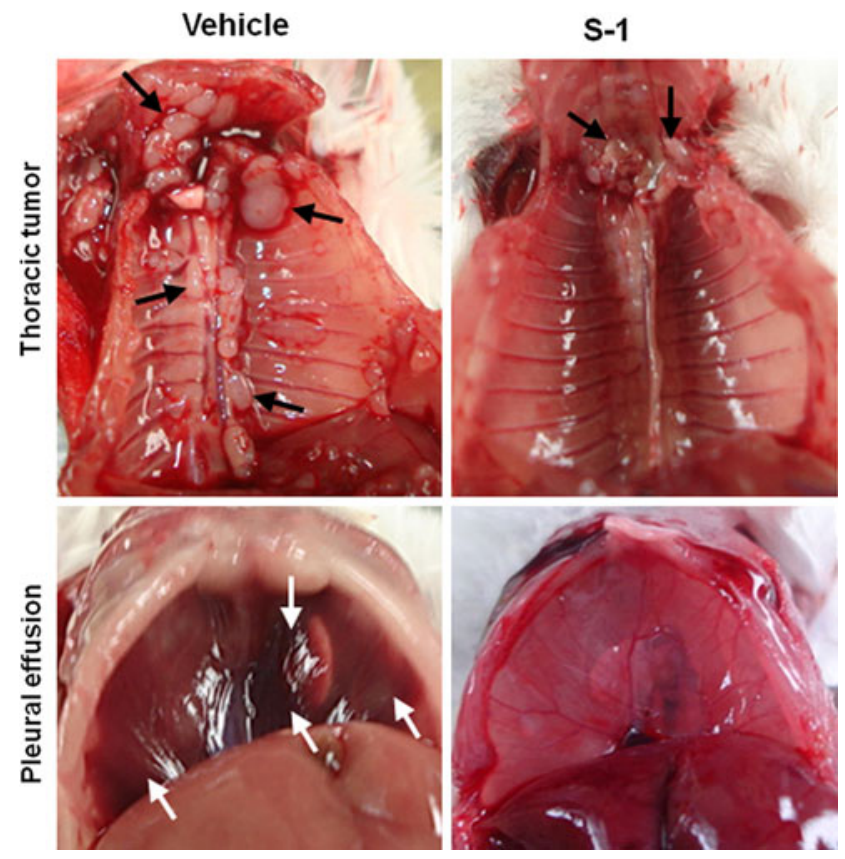

Fig. 3 Therapeutic effect of S-1 on the progression of Y-MESO-14 tumor in SCID mice. Y-MESO-14 cells developed thoracic tumors (upper left, black arrows) and pleural effusion (lower left, white arrows) in mice treated with vehicle. Treatment with S-1 significantly decreased the mass of tumors (upper right) and bloody pleural effusion (lower right)

bearing mice, treatment with $\mathrm{S}-1$ tended to reduce tumor weight and pleural effusion volume in the thoracic cavity, but not significant (Fig. 2c, d). S-1 had no obvious effect in inhibiting tumor growth in MSTO-211H cell-bearing mice (Fig. 2e, f). These results were consistent with the effect of 5-FU combined with CDHP on the proliferation of MPM cells in vitro. Thus, we used Y-MESO-14 cells for further investigation.

We next examined the dose-response relationship of S-1 in Y-MESO-14 cell-bearing mice. Treatment with S-1 from day 7 to 20 revealed dose-dependent inhibition of tumor growth of orthotopically implanted Y-MESO-14 cells in SCID mice (Fig. 4a, b). Particularly, the effect of S-1 at the dose of $10 \mathrm{mg} / \mathrm{kg} /$ day was significantly superior compared with that at the dose of $5 \mathrm{mg} / \mathrm{kg} /$ day in inhibiting tumor (Fig. 4a). On the other hand, S-1 was well tolerated in all set of experiments, as determined by the absence of weight loss or other signs of acute or delayed toxicity (data not shown). Therefore, treatment with $\mathrm{S}-1$ at the dose of $10 \mathrm{mg} / \mathrm{kg} /$ day for 14 days (day 7-20) was chosen for further experiments. Moreover, we also tested short treatment courses with a constant daily dose of $\mathrm{S}-1$ (10 $\mathrm{mg} / \mathrm{kg} /$ day $)$ for 10 days under two schedules of administration, running from day 7 to 16 and from day 11 to 20 . Interestingly, both schedules significantly diminished the weight of thoracic tumors and volume of pleural effusion produced by Y-MESO-14 cells (Fig. 5a, b). The schedule from day 11-20 appeared to be 

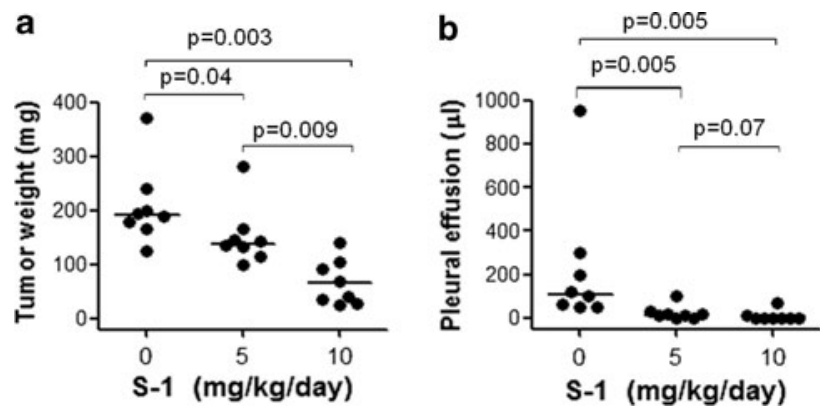

Fig. 4 The dose-response study of S-1 given for treatment of Y-MESO-14 cells implanted in SCID mice. Y-MESO-14 cells were inoculated into thoracic cavity of SCID mice on day 0 . The Y-MESO14 cell-inoculated mice were daily treated with vehicle or with various doses of S-1 from day 7 to 20 and sacrificed on day 21 . Treatment with S-1 was significantly effective to reduce tumor (a), and pleural effusion (b), in a dose dependent manner. The $P$ values were obtained from Holm's procedure (non-parametric Tukey test)
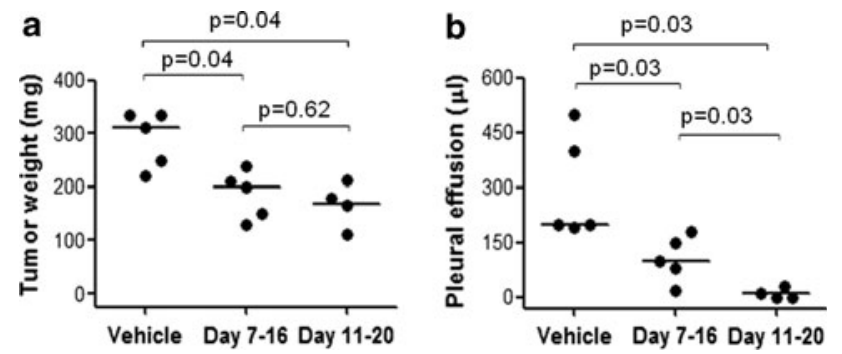

Fig. 5 Effect of various schedules of S-1 treatment on thoracic tumor and pleural effusion produced by Y-MESO-14 cells in SCID mice. Y-MESO-14 cells were inoculated into thoracic cavity of SCID mice on day 0 . The mice were treated with vehicle or S-1 $(10 \mathrm{mg} / \mathrm{kg})$ for 10 days under two schedules from day 7-16 and from day 11-20. Both these two treatment schedules resulted in significant reduction of tumor (a), and pleural effusion (b). The schedule from day 11-20 appeared to be more effective than the schedule from day 7-16 in reducing pleural effusion. The $P$ values were obtained from Holm's procedure (non-parametric Tukey test)

more effective than the schedule from day 7-16, at least in reducing pleural effusion $(P=0.03)$ (Fig. 5b). Furthermore, the effect of the schedule for 10 days from day 11-20 was comparable to that of the schedule of 14 days (data not shown). Hence, two regimens of S-1 $(10 \mathrm{mg} / \mathrm{kg} / \mathrm{day})$ for 14 days (day 7-20) and 10 days (day 11-20) were preferable for survival experiment.

Treatment with S-1 prolonged the survival of Y-MESO-14 cell-bearing mice

In the final experiment, we evaluated the survival benefit of S-1 on Y-MESO-14 cell-bearing mice. After tumor cell inoculation, the mice were treated with S-1 at the dose of $10 \mathrm{mg} / \mathrm{kg}$ for 10 days (day $11-20$ ) or 14 days (day 7-20) or vehicle. Interestingly, S-1 given by both treatment schedules significantly prolonged the survival of mice

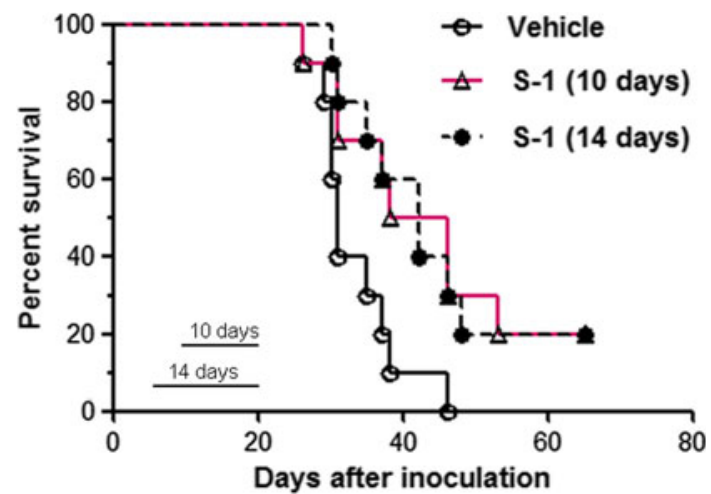

Fig. 6 The effect of S-1 administration on the survival of MPM cellbearing SCID mice. Y-MESO-14 cell-bearing mice were treated with vehicle or with $\mathrm{S}-1(10 \mathrm{mg} / \mathrm{kg}$, daily) for 10 days (day 11-20) or 14 days (day 7-20). There were significant differences between 10day treatment and vehicle groups $(P=0.02)$ and between 14-day treatment and vehicle groups $(P=0.02)$. The median survival times were 31, 42 and 42 days in vehicle, 10-day and 14-day treatment groups, respectively. The probability of survival was calculated with the Kaplan-Meier method, and differences between curves were evaluated with the log-rank test

compared with vehicle treatment $(P=0.02$ and 0.02$)$ (Fig. 6). The median survival times were 31,42 , and 42 days in vehicle, 10-day and 14-day S-1 treatment groups, respectively.

\section{Discussion}

The management of MPM is still challenging due to lack of sufficient treatment modalities. Recently, pemetrexed in combination with cisplatin has been approved as the firstline treatment in advanced stages of MPM. Although patients who were undergone this regimen have been reported to have a survival improvement (12.1 vs. 9.3 months) $[10,11]$, the outcome is still very poor. Therefore, new therapeutic strategies for the management of MPM are clearly urgent. In the present study, we demonstrated that S-1 had antitumor effect on human MPM cells and that it induced survival benefit in the orthotopic implantation model of human MPM. These findings strongly indicated that $\mathrm{S}-1$ is a useful therapeutic candidate against human MPM.

S-1 is a newly developed oral fluoropyrimidine derivative, containing CDHP which is an active modulator. CDHP is a strong inhibitor of 5-FU degradation by DPD in tumor cells, leading to enhance the antitumor activity of 5-FU, especially against tumor cells expressing high level of DPD [27]. Several lines of evidence have indicated the inverse correlation between DPD expression in tumor cells and response to 5-FU-based treatment [17]. In the present study, we demonstrated that DPD was expressed by three human MPM cell lines, Y-MESO-14, NCI-H290 and 
MSTO-211H cells, and that CDHP enhanced the in vitro antitumor activity of 5-FU in treatment of these MPM cells. By contrast, there was no enhancement of response to 5-FU by CDHP addition in human MPM cell lines with low expression of DPD (data not shown). Although DPD has been considered as an important predictive marker for S-1 efficacy in various cancers such as colon, gastric, lung cancers, and hepatocellular carcinoma [28, 29], to our knowledge, this is the first report that human MPM cells which expressed high level of DPD were more sensitive to CDHP-modified 5-FU treatment than to 5-FU alone. TP has also been reported to mediate the sensitivity of cancer cells to 5-FU. Schwartz et al. showed that the transfection of TP into human colon cancer cells, HT-29, increased the sensitivity to 5-FU [26]. The anabolic conversion of 5-FU into its active metabolites, such as FUTP or 5-fluoro-2'deoxyuridine- $5^{\prime}$-monophosphate (FdUMP), is essential for its action. TP catalyzes the conversion of 5-FU into $2^{\prime}$-deoxy-5-fluorouridine, which is converted directly to FdUMP by thymidine kinase. In this study, we found that Y-MESO-14 cells which co-express DPD and TP were more sensitive to in vitro treatment with 5-FU plus CDHP and in vivo treatment with $\mathrm{S}-1$ than the other two cell lines expressing only DPD but not TP (Figs. 1, 2). These findings indicated that the co-expression of DPD and TP might enhance the therapeutic efficacy of S-1 in human MPM cells.

Previously, we have established a novel orthotopic MPM model by implanting human MPM cells in the thoracic cavity of SCID mice [22]. The inoculated MPM cells were able to grow and subsequently produce thoracic tumors and bloody pleural effusion inside the thoracic cavity of mice. Several weeks after tumor cell inoculation, MPM cell-bearing mice would die of tumor progression, illustrating human patient-like features of MPM. This model was applicable to evaluate the therapeutic effect of anticancer drugs [19, 22, 23]. In the present study, by using this model, we evaluated the preclinical therapeutic efficacy of S-1 against human MPM cells. As expected, treatment with S-1 $(10 \mathrm{mg} / \mathrm{kg})$ for 14 days (day 7-20) remarkably inhibited the progression of Y-MESO-14 cells, which co-expressed DPD and TP, in mouse thoracic cavities by reducing thoracic tumor formation and bloody pleural effusion (Figs. 2a, b, 3). Moreover, the same schedule of S-1 treatment significantly prolonged the survival of Y-MESO-14 cell-bearing mice (Fig. 6). Clinically, as patients with MPM are often diagnosed at their advanced stages, most of such patients cannot receive sufficient treatment. To investigate whether S-1 could be effective in clinical relevant settings, we delayed the start of treatment and curtailed the duration. Importantly, the delayed and curtailed administration of S-1 $(10 \mathrm{mg} / \mathrm{kg})$ for 10 days (day 11-20) also significantly inhibited the tumor progression (Fig. 5) and prolonged the survival of Y-MESO-14 cell-bearing mice (Fig. 6). These results suggested that S-1 might be effective against human MPM even in clinical relevant settings.

In conclusion, we have investigated the therapeutic efficacy of S-1 against human MPM cells. S-1 had promising antitumor effect on human MPM cells with both DPD and TP expressions and prolonged the survival of human MPM cell-bearing mice. These findings suggest that S-1 may be a useful therapeutic agent for human MPM.

Acknowledgments This work was supported by Grants-in-Aid for Cancer Research from the Ministry of Education, Science, Sports and Culture of Japan. Grant support: Grants-in-Aid 17016051 for Cancer Research from the Ministry of Education, Science, Sports and Culture of Japan.

Conflict of interest S. Kakiuchi, Y. Nishioka, S. Akiyama and S. Sone received funding from Taiho Pharmaceutical Co., Ltd. T. Kuramoto received remuneration from Taiho Pharmaceutical Co., Ltd.

Open Access This article is distributed under the terms of the Creative Commons Attribution Noncommercial License which permits any noncommercial use, distribution, and reproduction in any medium, provided the original author(s) and source are credited.

\section{References}

1. Morinaga K, Kishimoto T, Sakatani M, Akira M, Yokoyama K, Sera Y (2001) Asbestos-related lung cancer and mesothelioma in Japan. Ind Health 39:65-74

2. Weiner SJ, Neragi-Miandoab S (2009) Pathogenesis of malignant pleural mesothelioma and the role of environmental and genetic factors. J Cancer Res Clin Oncol 135:15-27

3. Gasparrini A, Pizzo AM, Gorini G, Seniori Costantini A, Silvestri S, Ciapini C, Innocenti A, Berry G (2008) Prediction of mesothelioma and lung cancer in a cohort of asbestos exposed workers. Eur J Epidemiol 23:541-546

4. Pelucchi C, Malvezzi M, La Vecchia C, Levi F, Decarli A, Negri E (2004) The mesothelioma epidemic in Western Europe: an update. Br J Cancer 90:1022-1024

5. Peto J, Decarli A, La Vecchia C, Levi F, Negri E (1999) The European mesothelioma epidemic. Br J Cancer 79:666-672

6. Kanazawa N, Ioka A, Tsukuma H, Ajiki W, Oshima A (2006) Incidence and survival of mesothelioma in Osaka, Japan. Jpn J Clin Oncol 36:254-257

7. Murayama T, Takahashi K, Natori Y, Kurumatani N (2006) Estimation of future mortality from pleural malignant mesothelioma in Japan based on an age-cohort model. Am J Ind Med 49:1-7

8. Tsiouris A, Walesby RK (2007) Malignant pleural mesothelioma: current concepts in treatment. Nat Clin Pract Oncol 4:344-352

9. Goudar RK (2008) Review of pemetrexed in combination with cisplatin for the treatment of malignant pleural mesothelioma. Ther Clin Risk Manag 4:205-211

10. Hazarika M, White RM, Johnson JR, Pazdur R (2004) FDA drug approval summaries: pemetrexed (Alimta). Oncologist 9:482-488

11. Vogelzang NJ, Rusthoven JJ, Symanowski J, Denham C, Kaukel E, Ruffie P, Gatzemeier U, Boyer M, Emri S, Manegold C, Niyikiza C, Paoletti P (2003) Phase III study of pemetrexed in 
combination with cisplatin versus cisplatin alone in patients with malignant pleural mesothelioma. J Clin Oncol 21:2636-2644

12. Shirasaka T, Shimamato Y, Ohshimo H, Yamaguchi M, Kato T, Yonekura K, Fukushima M (1996) Development of a novel form of an oral 5-fluorouracil derivative (S-1) directed to the potentiation of the tumor selective cytotoxicity of 5 -fluorouracil by two biochemical modulators. Anticancer Drugs 7:548-557

13. Saif MW, Syrigos KN, Katirtzoglou NA (2009) S-1: a promising new oral fluoropyrimidine derivative. Expert Opin Investig Drugs $18: 335-348$

14. Yoshisue K, Hironaga K, Yamaguchi S, Yamamoto A, Nagayama S, Kawaguchi Y (2000) Reduction of 5-fluorouracil (5-FU) gastrointestinal (GI) toxicity resulting from the protection of thymidylate synthase (TS) in GI tissue by repeated simultaneous administration of potassium oxonate (Oxo) in rats. Cancer Chemother Pharmacol 46:51-56

15. Shirasaka T, Nakano K, Takechi T, Satake H, Uchida J, Fujioka A, Saito H, Okabe H, Oyama K, Takeda S, Unemi N, Fukushima M (1996) Antitumor activity of 1 M tegafur-0.4 M 5-chloro-2, 4dihydroxypyridine-1 $\mathrm{M}$ potassium oxonate (S-1) against human colon carcinoma orthotopically implanted into nude rats. Cancer Res 56:2602-2606

16. Obara S, Yamamoto K, Hosogai N, Yoshimura Y (2005) Evaluation of TS-1 based treatment and expression of thymidylate synthase and dihydropyrimidine dehydrogenase on oral squamous cell carcinoma. Oral Oncol 41:276-282

17. Fujiwara H, Terashima M, Irinoda $T$, Takagane A, Abe K, Nakaya T, Yonezawa H, Oyama K, Takahashi M, Saito K, Takechi T, Fukushima M, Shirasaka T (2003) Superior antitumour activity of S-1 in tumours with a high dihydropyrimidine dehydrogenase activity. Eur J Cancer 39:2387-2394

18. Nishimura G, Yanoma S, Mizuno H, Satake K, Taguchi T, Ikeda Y, Tsukuda M (2000) Therapeutic effect of 1 M tegafur-0.4 M 5chloro-2, 4-dihydroxypridine-1 $\mathrm{M}$ potassium oxonate (S-1) on head and neck squamous carcinoma cells. Cancer Lett 159:1-7

19. Ikuta K, Yano S, Trung VT, Hanibuchi M, Goto H, Li Q, Wang W, Yamada T, Ogino H, Kakiuchi S, Uehara H, Sekido Y, Uenaka T, Nishioka Y, Sone S (2009) E7080, a multi-tyrosine kinase inhibitor, suppresses the progression of malignant pleural mesothelioma with different proangiogenic cytokine production profiles. Clin Cancer Res 15:7229-7237

20. Green LM, Reade JL, Ware CF (1984) Rapid colorimetric assay for cell viability: application to the quantitation of cytotoxic and growth inhibitory lymphokines. J Immunol Methods 70:257-268
21. Uchimiya H, Furukawa T, Okamoto M, Nakajima Y, Matsushita S, Ikeda R, Gotanda T, Haraguchi M, Sumizawa T, Ono M, Kuwano M, Kanzaki T, Akiyama S (2002) Suppression of thymidine phosphorylase-mediated angiogenesis and tumor growth by 2-deoxy-L-ribose. Cancer Res 62:2834-2839

22. Nakataki E, Yano S, Matsumori Y, Goto H, Kakiuchi S, Muguruma $\mathrm{H}$, Bando $\mathrm{Y}$, Uehara $\mathrm{H}$, Hamada $\mathrm{H}$, Kito K, Yokoyama A, Sone S (2006) Novel orthotopic implantation model of human malignant pleural mesothelioma (EHMES-10 cells) highly expressing vascular endothelial growth factor and its receptor. Cancer Sci 97:183-191

23. Li Q, Yano S, Ogino H, Wang W, Uehara H, Nishioka Y, Sone S (2007) The therapeutic efficacy of anti vascular endothelial growth factor antibody, bevacizumab, and pemetrexed against orthotopically implanted human pleural mesothelioma cells in severe combined immunodeficient mice. Clin Cancer Res 13:5918-5925

24. Longley DB, Harkin DP, Johnston PG (2003) 5-fluorouracil: mechanisms of action and clinical strategies. Nat Rev Cancer 3:330-338

25. Chujo $M$, Miura $T$, Kawano $Y$, Miyawaki $M$, Imakiire $T$, Hayashita Y, Kawahara K (2006) Thymidine phosphorylase levels and dihydropyrimidine dehydrogenase levels in non-small cell lung cancer tissues. Oncol Rep 16:777-780

26. Schwartz EL, Baptiste N, Wadler S, Makower D (1995) Thymidine phosphorylase mediates the sensitivity of human colon carcinoma cells to 5-fluorouracil. J Biol Chem 270:19073-19077

27. Takechi T, Fujioka A, Matsushima E, Fukushima M (2002) Enhancement of the antitumour activity of 5-fluorouracil (5-FU) by inhibiting dihydropyrimidine dehydrogenase activity (DPD) using 5-chloro-2, 4-dihydroxypyridine (CDHP) in human tumour cells. Eur J Cancer 38:1271-1277

28. Inoue K, Takao M, Watanabe F, Tarukawa T, Shimamoto A, Kaneda M, Sakai T, Fukushima M, Shimpo H, Yada I (2005) Role of dihydropyrimidine dehydrogenase inhibitory fluoropyrimidine against non-small cell lung cancer-in correlation with the tumoral expression of thymidylate synthase and dihydropyrimidine dehydrogenase. Lung Cancer 49:47-54

29. Takechi T, Okabe H, Ikeda K, Fujioka A, Nakagawa F, Ohshimo H, Kitazato K, Fukushima M (2005) Correlations between antitumor activities of fluoropyrimidines and DPD activity in lung tumor xenografts. Oncol Rep 14:33-39 